\title{
Inherited Cardiomyopathies
}

\author{
Jeffrey A. Towbin, MD
}

\begin{abstract}
Cardiomyopathies (ie, diseases of the heart muscle) are major causes of morbidity and mortality. A significant percentage of patients with cardiomyopathies have genetic-based, inheritable disease and, over the past 2 decades the genetic causes of these disorders have been increasingly discovered. The genes causing these disorders when they are mutated appear to encode proteins that frame a "final common pathway" for that specific disorder, but the specifics of the phenotype, including age of onset, severity, and outcome is variable for reasons not yet understood. The "final common pathways" for the classified forms of cardiomyopathy include the sarcomere in the primarily diastolic dysfunction disorders hypertrophic cardiomyopathy and restrictive cardiomyopathy, the linkage of the sarcomere and sarcolemma in the systolic dysfunction disorder dilated cardiomyopathy, and the desmosome in arrhythmogenic cardiomyopathy. Left ventricular noncompaction cardiomyopathy (LVNC) is an overlap disorder and it appears that any of these "final common pathways" can be involved depending on the specific form of LVNC. The genetics and mechanisms responsible for these clinical phenotypes will be described. (Circ J 2014; 78: 2347-2356)
\end{abstract}

Key Words: Cardiomyopathy; Genetics; Heart failure

C ardiomyopathies are major causes of morbidity and mortality and over the past 25 years, limited improvements in outcome have been reported., ${ }^{1,2}$ However, improvements in the understanding of the major forms of cardiomyopathy has occurred over that time, in large part because of advances in imaging, genetics and genomics. ${ }^{3,4}$ A new classification scheme for the cardiomyopathies was recently developed in which 5 forms of disease were formally classified: dilated cardiomyopathy (DCM), hypertrophic cardiomyopathy (HCM), restrictive cardiomyopathy (RCM), arrhythmogenic ventricular cardiomyopathy (AVC), and left ventricular noncompaction cardiomyopathy (LVNC). ${ }^{5}$ These are further classified into genetic/inherited forms and acquired/non-inherited forms. All forms occur at all ages except AVC, which is almost always identified in teenagers and young adults.

Our understanding of the genetic causes of cardiomyopathy has expanded significantly over the past decade. In many cases, the genetic and mechanistic causes of these disorders follow a disturbance in a particular, disease-specific "final common pathway". ${ }^{6}$ For instance, $\mathrm{HCM}$ is now viewed as predominantly an inherited abnormality of contractile protein function ("disease of the sarcomere"). Progress in understanding the genetics of familial DCM has been complicated by its heterogeneous etiologies, but a genetic cause is thought to occur in approximately $50 \%$ of subjects, higher in children. ${ }^{3-5}$ The genes identified to date as causative appear to disturb the functional link between the cytoskeleton and sarcomere most commonly. ${ }^{4}$ Multiple genes have been identified for AVC, most resulting in disturbed desmosome/intercalated disk function. ${ }^{4,7}$ Although understanding the genetic basis for the development of RCM and LVNC has been more elusive, genes for both have been identified and appear to include sarcomere dysfunction as a critical factor. ${ }^{8}$

In this review, the current genetic knowledge of each cardiomyopathy phenotype is covered and I will describe how disruption of these "final common pathways" leads to DCM (sarcolemma-sarcomere link), HCM (sarcomere), RCM (sarcomere), AVC (desmosome), and LVNC (sarcolemma and sarcomere).

\section{Final Common Pathways}

Over the past 2 decades, many of the genes responsible for the development of the different cardiomyopathies have been identified. In an initial attempt to target genes for genetic study, my group developed the "final common pathway" hypothesis, which stated that genes encoding proteins with similar functions or involved in the same pathway are responsible for a particular disease or syndrome phenotype. ${ }^{6}$ As a result, we and others identified structure-function similarities of proteins encoded by genes that, when disrupted, led to a somewhat predictable gross clinical phenotype. For instance, the genes identified as causative for inherited arrhythmia disorders tend to encode for ion channels: those for HCM encode for sarcomeric proteins, and AVCs by genes encoding cell-cell junction proteins, as examples (Figure 1). In addition, it appears that the protein disturbed by the mutated gene directly disrupts the normal function of the structures in which it is integrated (eg, the sarcomere in HCM when the mutated gene encodes a sarcomeric protein) most commonly but, in some instances, disrupt a binding partner protein, which causes downstream disturbance of the "final common pathway" (eg, a Z-disk protein disrupting the cell-cell junction via a maladaptive binding to desmin,

Received August 11, 2014; accepted August 11, 2014; released online September 2, 2014

The Heart Institute, Cincinnati Children's Hospital Medical Center, Cincinnati, OH, USA

Mailing address: Jeffrey A. Towbin, MD, Professor \& Kindervelt-Samuel Kaplan Chair in Pediatric Cardiology and Cardiac Research,

Cincinnati Children's Hospital, 3333 Burnet Avenue, Cincinnati, OH 45229, USA. E-mail: jeffrey.towbin@cchmc.org

ISSN-1346-9843 doi:10.1253/circj.CJ-14-0893

All rights are reserved to the Japanese Circulation Society. For permissions, please e-mail: cj@j-circ.or.jp 


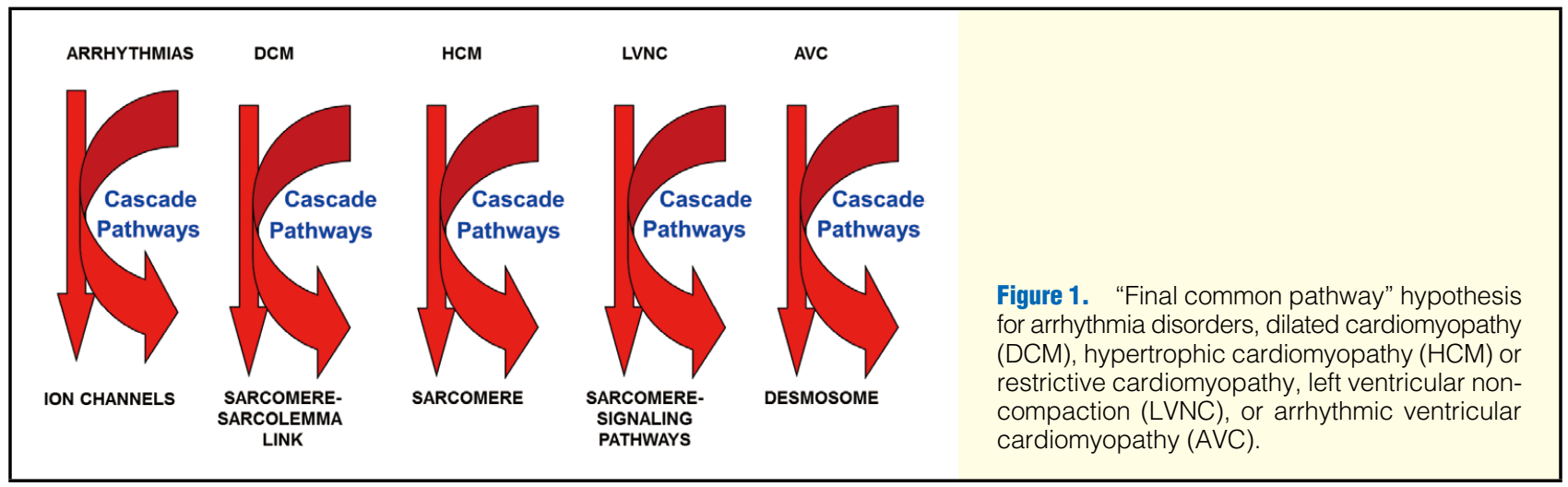

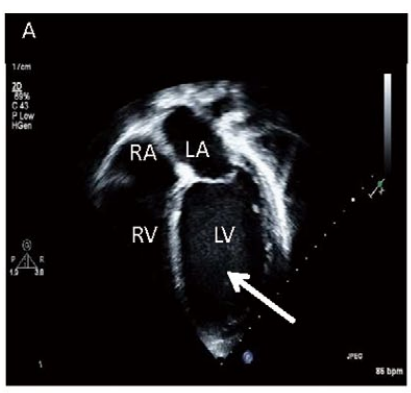

DCM

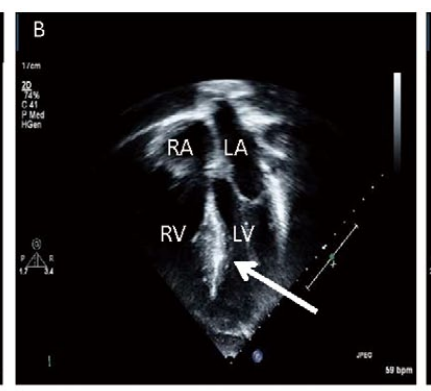

$\mathrm{HCM}$

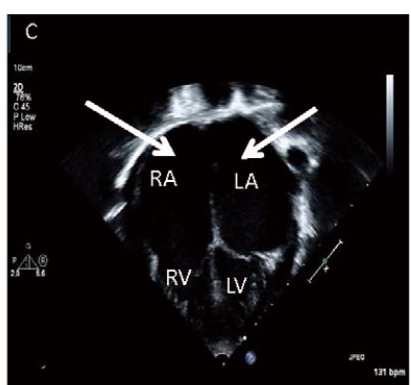

$\mathrm{RCM}$

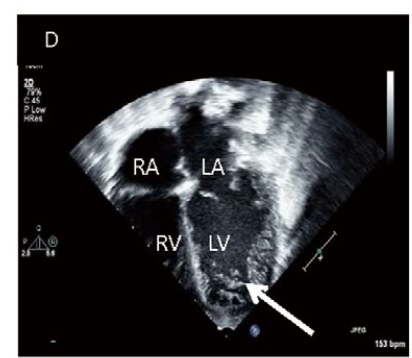

LVNC

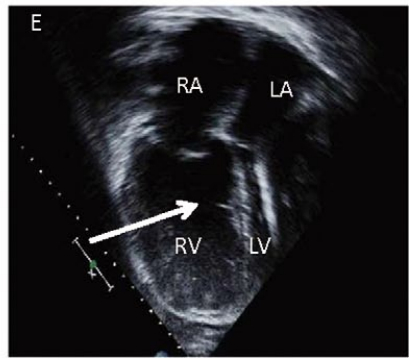

AVC

Figure 2. Echocardiographic features of cardiomyopathies. (A) 4-chamber view of dilated cardiomyopathy (DCM). Note the dilated left ventricle (arrow). (B) 4-chamber view of hypertrophic cardiomyopathy (HCM). Note the thickened mid-portion of the interventricular septum (arrow). (C) 4-chamber view of restrictive cardiomyopathy (RCM). Note the dilated atria (RA, LA; arrows). (D) 4-chamber view of left ventricular noncompaction cardiomyopathy (LVNC). Note the hypertrabaeculation in the LV (arrow). (E) 4-chamber view of arrhythmogenic right ventricular cardiomyopathy (ARVC). Note the dilated, trabeculated RV (arrow); Commonly, an aneurysm of the RV or RV outflow tract can be seen, particularly by MRI.

which negatively interacts with a desmosomal protein causing AVC) (Figure 1).

\section{DCM}

DCM is the most common cardiomyopathy, accounting for approximately $55 \%$ of cardiomyopathies..$^{5}$ The annual incidence is $2-8 / 100,000(0.57 / 100,000 /$ year in children $)$ with an estimated prevalence of $1 / 2,500$ population. ${ }^{5,9}$ The percentage of cases with a genetic etiology is approximately $30-50 \%$ based on the presence of a family history. ${ }^{10-12} \mathrm{DCM}$ is characterized by LV dilation and systolic dysfunction (a reduction in myocardial force generation) and is the most common indication for cardiac transplantation (Figure 2). ${ }^{5,9-12}$ Clinical manifestations include heart failure (HF), thromboembolism, and sudden cardiac death (SCD). The age at onset includes newborn through late adulthood, although most patients are diagnosed between $20-50$ years of age. ${ }^{12}$

The genetic forms of DCM usually result from mutated genes encoding 2 major subgroups of proteins: cytoskeletal and sarcomeric proteins. ${ }^{3,4,6,13}$ DCM can also present with muscular involvement and may be the presenting or primary clinical feature of several multisystem conditions, including EmeryDreifuss muscular dystrophy (EDMD), Barth syndrome, myofibrillar myopathy, limb-girdle muscular dystrophy (LGMD), and Duchenne or Becker muscular dystrophy (DMD/BMD). ${ }^{14}$ 


\section{Genetics of DCM}

Inherited, familial DCM (FDCM) has been shown to occur in $30-50 \%$ of cases of DCM, with autosomal dominant inheritance being the predominant pattern of transmission; X-linked, autosomal recessive, and mitochondrial inheritance forms are less common. ${ }^{10-12,15,16}$ Over the past $20+$ years, substantial progress has been made in understanding of the genetic etiology of FDCM (Table 1). Initial progress was made in the early 1990s studying families with X-linked forms of DCM, with the autosomal dominant forms unraveling shortly thereafter.

X-linked DCM, occurring in males in the teen years and early twenties with rapid progression from HF to either death from arrhythmia or transplantation, is distinguished by elevated serum creatine kinase muscle isoforms (CK-MM). ${ }^{16,17}$ Female carriers develop milder, slowly progressive DCM (5th decade). My group in 1993 identified the disease-causing gene as dystrophin and demonstrated significant reduction or absence of dystrophin protein in the heart. ${ }^{17}$ These findings were later confirmed by Muntoni et $\mathrm{al}^{18}$ and others, ${ }^{19}$ with mutations generally occurring in the 5' end of the gene. Dystrophin links the sarcomere to the sarcolemma and extracellular matrix (Figure 3). ${ }^{16}$ When mutated, dystrophin causes DMD/BMD, which are skeletal myopathies that present in males early in life with elevated CK-MM and lead to the early need for wheelchairs (DMD, before age 12 years; BMD, older than 16 years of age), ${ }^{20-22}$ with DCM usually occurring between 10 and 25 years of age. ${ }^{16-22}$

The most common form of inherited DCM has autosomal dominant inheritance, ${ }^{6,13,15}$ presenting either as classic "pure" DCM or DCM associated with early-onset conduction system disease (CDDC). Genetic heterogeneity exists for autosomal dominant DCM, with more than 40 genes identified for DCM and CDDC, 3,4,13,23,24 and most of these genes encoding cytoskeletal, sarcomeric, or Z-disk proteins, although mutations in a small number of ion channel-encoding and desmosome-encoding genes have also been identified (Table 1). These include genes primarily encoding cytoskeletal ( $\delta$-sarcoglycan (SGCD), $\beta$-sarcoglycan (SGCB), desmin (DES), lamin A/C (LMNA), vinculin), sarcomeric/myofibrillar ( $\alpha$-cardiac actin (ACTC), troponin T (TNNT2), troponin I (TNNI3), $\beta$-myosin heavy chain (MYH7), myosin binding protein $\mathrm{C}$, and $\alpha$-tropomyosin (TPM1)), and Z-disk proteins (muscle LIM protein (MLP)/ cysteine and glycine-rich protein 3 (CSRP3), titin (TTN), telethonin/TCAP, $\alpha$-actinin-2 (ACTN2), nebulette (NEBL), myopalladin (MYPN), ANKRD1/CARP, and ZASP/LIMdomain binding 3 (LBD3)) (Table 1, Figure 3). Ion channelencoding genes identified to date include the cardiac sodium channel gene SCN5A and calcium homeostasis regulator phospholamban (PLN), ${ }^{23,24}$ and associated desmosome-encoding genes including desmoplakin (DSP), desmoglein-2 (DSG2), and desmocolin-2 (DSC2) have also been shown to result in a DCM phenotype (Table 1 , Figure 3 ). ${ }^{25}$ In the case of CDDC, LMNA is the most common cause, but other causes include DES and SCN5A (Table 1, Figure 3). ${ }^{26,27}$ Mechanistically, cytoskeletal proteins are thought to cause defects of force transmission, resulting in the DCM phenotype, whereas defects of force generation have been speculated to be associated with sarcomere protein-induced DCM. ${ }^{28,29}$ The altered desmosomal proteins appear to disrupt the links between the intercalated disk, Z-disk, and sarcomere. ${ }^{30,31}$ Purevjav et al recently showed that a gene mutation may disrupt protein binding partners and, depending on this interaction, differential phenotypes and severity may occur. ${ }^{32,33}$

Mutations in the sarcomere may produce variable forms of cardiomyopathy (Tables 1-4, Figure 3 ). As previously noted,

\begin{tabular}{|c|c|}
\hline Gene & Gene name \\
\hline ABCC9 & ATP-binding cassette, subfamily $C$, member 9 \\
\hline ACTC & $a$-Cardiac actin \\
\hline ACTN2 & a-Actinin2 \\
\hline ANKRD1 & Cardiac ankyrin repeat, domain 1 \\
\hline BAG3 & BCL2-associated athanogene 3 \\
\hline CSRP3 & Cysteine and glycine-rich protein 3 \\
\hline CTF1 & Cardiotrophin 1 \\
\hline DES & Desmin \\
\hline DYS & Dystrophin \\
\hline DNAJC19 & DnaJ (Hsp40) homolog, subfamily C, member 19 \\
\hline DSC2 & Desmocollin 2 \\
\hline DSG2 & Desmoglin 2 \\
\hline DSP & Desmoplakin \\
\hline EMD & Emerin \\
\hline EYA4 & Eyes absent homolog 4 \\
\hline FHL2 & Four and a half LIM domains 2 \\
\hline FKTN & Fukutin \\
\hline FOXD4 & Forkhead box D4 \\
\hline LAMA4 & a4-Laminin \\
\hline LAMP2 & Lysosomal-associated membrane protein 3 \\
\hline LDB3 & LIM-domain binding 3 \\
\hline LMNA & Lamin $\mathrm{A} / \mathrm{C}$ \\
\hline MYBPC3 & Myosin binding protein $\mathrm{C}$ \\
\hline MYH6 & $\beta$-Myosin heavy chain 6 \\
\hline MYH7 & $\beta$-Myosin heavy chain 7 \\
\hline MYPN & Myopalladin \\
\hline NEBL & Nebulette \\
\hline NEXN & Nexilin (F actin-binding protein) \\
\hline PLN & Phospholamban \\
\hline PSEN1 & Presenilin 1 \\
\hline PSEN2 & Presenilin 2 \\
\hline RBM20 & RNA binding motif protein 20 \\
\hline SCN5A & Voltage-gated sodium channel, $a$ subunit \\
\hline SDHA & $\begin{array}{l}\text { Succinate dehydrogenase complex, subunit A, } \\
\text { flavoprotein }\end{array}$ \\
\hline SGCD & $\delta$-Sarcoglycan \\
\hline SYNE1 & Spectrin repeat containing nuclear protein 1 \\
\hline SYNE2 & Spectrin repeat containing nuclear protein 2 \\
\hline $\mathrm{TAZ}$ & Tafazzin \\
\hline TCAP & Titin-cap (Telethonin) \\
\hline TMPO & Thymopoeitin \\
\hline TNNC1 & Cardiac troponin C, type 1 \\
\hline TNNI3 & Cardiac troponin I, type 3 \\
\hline TNNT2 & Cardiac troponin T, type 2 \\
\hline TPM1 & $a$-Tropomyosin 1 \\
\hline TTN & Titin \\
\hline TTR & Transthyretin \\
\hline VCL & Vinculin \\
\hline
\end{tabular}

abnormalities in the force generation or transmission are thought to contribute to the development of DCM. ${ }^{28,29,34,35} \alpha$-Cardiac actin, a sarcomeric thin filament protein that interacts with tropomyosin and the troponin complex, links the sarcomere to the sarcolemma via its binding to the $\mathrm{N}$-terminus of dystrophin. DCM-causing actin mutations disturb dystrophin-actin binding, ${ }^{36,37}$ causing force transmission abnormalities and DCM. 


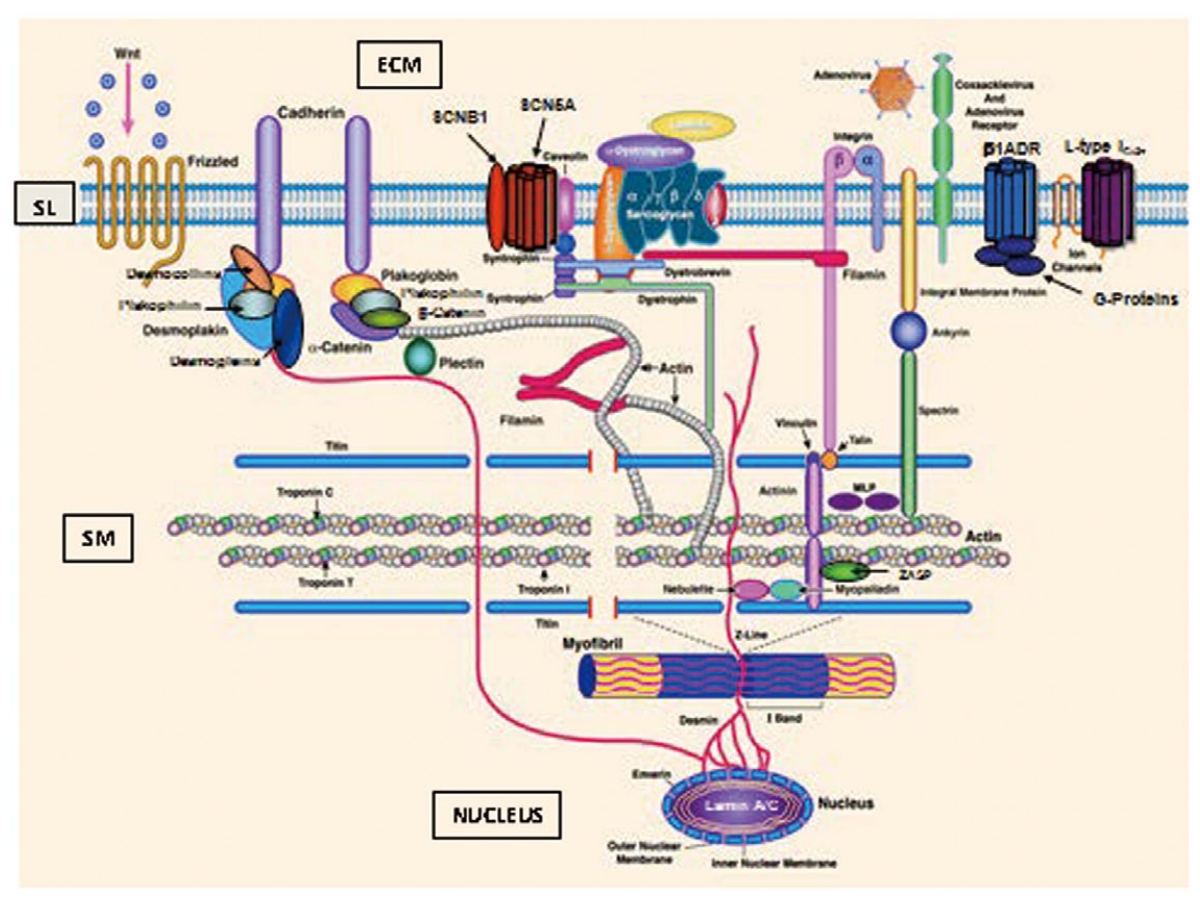

Figure 3. Cardiac myocyte cytoarchitecture. Schematic of key proteins of the extracellular matrix (ECM), sarcolemma (SL), sarcomere (SM), and nucleus, and some of their protein-protein interactions. Note the SL proteins include ion channels such as SCN5A, L-type calcium channels and others, as well as the dystrophin-associated binding proteins that interact with dystrophin and other cytoplasmic cytoskeletal proteins (dystroglycans, sarcoglycans, syntrophins, dystrobrevin, sarcospan, caveolin), and cadherins that bind with desmosomal proteins (desmocollin, plakophillin, desmoplakin, plakoglobin). The integral SL membrane proteins interact with the ECM via a-dystroglycan-laminin $a 2$ connections. The SM includes thick and thin filament contractile proteins and Z-disk proteins. The amino-terminus of dystrophin binds actin and connects dystrophin with the SM intracellularly, the SL and ECM. The nucleus includes the important membrane proteins, lamin A/C and emerin. The intermediate filament protein, desmin, is another important and prominent linker protein. MLP, muscle LIM protein.

Further, actin interacts in the sarcomere with troponin $\mathrm{T}$ and MYH7; mutations in these genes cause DCM or HCM, depending on the position of the mutation ${ }^{37}$ via development of force generation abnormalities. For MYH7, this probably occurs by perturbing the actin-myosin interaction or altering cross-bridge movement during contraction. ${ }^{34-37}$ TNNT2 mutations disrupt calcium-sensitive troponin C binding. ${ }^{34-37}$ Mutations in PLN have also been identified, which further supports calcium handling as a potentially important mechanism in DCM development. ${ }^{34-37}$ TPM1 mutations alter its surface charge, causing impaired interaction with actin and potentially changing its secondary structure, its binding to actin and position on the thin filament, and alternating actin-myosin interactions and myofilament $\mathrm{Ca}^{2+}$ sensitivity.

Another molecular level target for DCM is the Z-disk. ${ }^{38-40}$ Knoll et al identified mutations in MLP/CSPR3, which disturbs its interaction with $\mathrm{TCAP}^{39}$ and its stretch sensor activity. Mutations in CSPR3 cause abnormalities in the T-tubule system and Z-disk architecture as well. ${ }^{41}$ Mutations in ACTN2, which binds CSPR3, is involved in crosslinking actin filaments, and shares a common actin-binding domain with dystrophin. In addition, ACTN2 mutations disrupt CSPR3 binding and stretch sensing. ${ }^{38-41}$ Mutations in ZASP/LBD3 cause DCM and LVNC, as well as myofibrillar myopathy. ${ }^{38-40,42}$ This protein, which interacts with ACTN2, the FATZ/calsarcin/myozenin protein family, the myotilin (myotilin, myopalladin, palladin) family, and TCAP that together form a complex with the car- diac sodium channel, NEBL, and phosphoglucomutase 1, disrupts the actin cytoskeleton when mutated. ${ }^{43} \mathrm{TTN}$, encoding a giant sarcomeric cytoskeletal protein, contributes to the maintenance of sarcomere organization and myofibrillar elasticity, and interacts with these proteins at the Z-disk/I-band transition zone and causes DCM or AVC when mutated. ${ }^{44}$

Because of significant locus and allelic heterogeneity, genetic testing for DCM has been of limited utility, with pathogenic variants identified in $17-40 \%$ of cases using current 40 gene panels, with most genes contributing only a small percentage of pathogenic variants. ${ }^{4,13,23,24}$ Clear genotype-phenotype correlations are rare.

\section{Muscle Is Muscle: Cardiomyopathy and Skeletal Myopathy Genes Overlap}

Interestingly, nearly all of the genes identified for inherited DCM are also known to cause skeletal myopathy in humans and/or mouse models: dystrophin mutations cause DMD/BMD; SGCD causes LGMD2F; LMNA causes autosomal dominant EDMD and LGMD1B; ACTC and DES cause nemaline myopathy. In addition, taffazin (TAZ), $\alpha$-dystrobrevin, LBD3, CSRP3, ACTN2, TTN, and SGCB mutations also cause skeletal myopathy, suggesting that cardiac and skeletal muscle function is interrelated; skeletal muscle fatigue seen in patients with DCM with and without HF may be related to primary skeletal muscle disease and not only cardiac dysfunction. It also sug- 


\begin{tabular}{ll} 
Table 2. Genetics of Hypertrophic Cardiomyopathy \\
\multicolumn{1}{c}{ Gene } & \multicolumn{1}{c|}{ Gene name } \\
ACTC & a-Cardiac actin \\
ACTN2 & a-Actinin2 \\
ANKRD1 & Cardiac ankyrin repeat, domain 1 \\
CAV3 & Caveolin 3 \\
COX15 & COX 15 homolog, cytochrome C oxidase assembly \\
& protein \\
CRYAB & Crystallin aB \\
CSRP3 & Cysteine and glycine-rich protein 3 \\
GLA & $a$-Galactosidase \\
LAMP-2 & Lysomal-associated membrane protein 2 \\
MYBPC3 & Myosin binding protein C \\
MYH6 & -Myosin heavy chain 6 \\
MYH7 & -Myosin heavy chain 7 \\
MYL2 & Myosin regulatory light chain 2, slow \\
MYL3 & Myosin light chain 3, slow \\
MYLK2 & Myosin light chain kinase 2 \\
MYO6 & Unconventional myosin VI \\
MYOZ2 & Myozenin 2 \\
NEXN & Nexilin (F actin-binding protein) \\
PLN & Phospholamban \\
PRKAG2 & AMP=activated protein kinase, V2, non-catalytic \\
& subunit \\
TNNC1 & Cardiac troponin C, type 1 \\
TAZ & Tafazzin \\
TCAP & Titin-cap (Telethonin) \\
TNNI3 & Cardiac troponin I, type 3 \\
TNNT2 & Cardiac troponin T, type 2 \\
TPM1 & $a$-Tropomyosin 1 \\
TTN & Titin \\
TTR & Transthyretin \\
VCL & Vinculin \\
\hline
\end{tabular}

gests that striated muscle dysfunction results from disturbed "final common pathways" and both sets of muscles should be evaluated in DCM.

\section{HCM}

HCM is characterized by asymmetric or concentric wall thickening (Figure 2) in the absence of an underlying systemic condition or other cardiac disease..$^{5,6,13,16,45}$ The major effects of this disorder on human health are its predilection to be inherited, its reputation as the most common cause of SCD in young, healthy individuals, and its potential to develop HF because of diastolic factors or development of systolic dysfunction..$^{5,46}$

\section{Genetics of Familial HCM}

HCM is among the most common inherited cardiac disorders, with a prevalence of $1 / 500$ in young adults. ${ }^{5}$ During the past $20+$ years, molecular genetic studies have given important insights into the pathogenesis of HCM and provided new perspectives for the diagnosis and management of affected patients. Genetic causes for HCM have been described, with over 20 genes discovered to date, most affecting the sarcomere; however, mutations in genes encoding proteins of the Z-disk or intracellular calcium modulators have also been identified (Table 2). Eight causative genes encode sarcomere proteins, with most $(\sim 80 \%)$ mutations identified in the MYH7 and

\begin{tabular}{|ll|}
\hline \multicolumn{2}{|c|}{ Table 3. Genetics of Restrictive Cardiomyopathy } \\
ACTC1 & \multicolumn{1}{c|}{ Gene name } \\
BAG3 & BCL2-asdiac actin \\
DES & Desmin \\
GLA & $a$-Galactosidase \\
MYH7 & $\beta$-Myosin heavy chain 7 \\
MYL2 & Myosin regulatory light chain 2, slow \\
MYL3 & Myosin light chain 3, slow \\
MYPN & Myopalladin \\
TNNI3 & Cardiac troponin I, type 3 \\
TNNT2 & Cardiac troponin T, type 2 \\
TPM1 & $\alpha$-Tropomyosin 1 \\
TTN & Titin \\
TTR & Transthyretin \\
\hline
\end{tabular}

\begin{tabular}{|ll|}
\hline \multicolumn{2}{|c|}{ Gene } \\
Cable 4. Genetics of Left Ventricular Noncompaction \\
ACTC1 & \multicolumn{1}{c|}{ Gene name } \\
CASQ2 & Cardiac calsequestrin 2 \\
DTNA & $a$-Dystrobrevin \\
DYS & Dystrophin \\
GLA & $a$-Galactosidase \\
LDB3 & LIM-domain binding 3 \\
LMNA & Lamin A/C \\
MYBPC3 & Myosin binding protein C \\
MYH7 & $\beta$-Myosin heavy chain 7 \\
TAZ & Tafazzin \\
TNNT2 & Cardiac troponin T, type 2 \\
\hline
\end{tabular}

MYBPC3 genes (Figure 3). ${ }^{4,5,13,45}$ Mutations identified in sarcomeric genes are typically single nucleotide substitutions and in most instances the mutant protein is thought to incorporate into the sarcomere, exerting a poison peptide effect (dominant negative mutations), with the only exception being MYBPC3, where deletions or insertions leading to a frameshift (ie, a truncated protein with no function), resulting in haploinsufficiency occur. ${ }^{47}$ In addition to defects in the sarcomere-encoding genes, $\mathrm{HCM}$ patients have been identified hosting mutations in Z-disk and other nonsarcomere-encoding genes. ${ }^{4,13,32,48}$ The giant protein titin and its interactive Z-disc proteins, including MLP, ZASP, telethonin, nexilin, myopalladin, myozenin- $2, \alpha$-actinin 2, CARP, and vinculin, have been identified as causes of HCM when the respective gene is mutated ${ }^{48}$ (Table 2, Figure 3). For Z-disk and calcium modulator genes, the specific mechanism has not been clearly elucidated.

Recent clinical guidelines for HCM recommend comprehensive testing for 5 genes (MYBPC3, MYH7, TNNI3, TNNT2, and TPM1), although current Nexgen sequencing approaches have facilitated much broader testing panels to be widely available from commercial laboratories ${ }^{19}$ (http://www.genetests.org and http://www.ncbi.nlm.nih.gov/gtr). Currently, genetic testing for HCM is primarily used to identify families with a detectable genetic cause of disease and to screen at-risk family members. In the clinic at the Heart Institute, mutations are seen in approximately $65-70 \%$ of all subjects. The utility of genetic test results in guiding clinical management is limited because of limited genotype-phenotype correlations. Although almost 

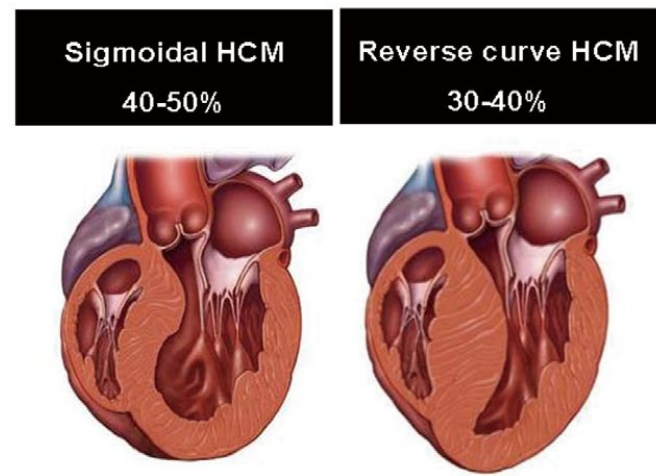

$\sim 10 \%$ Myofilament

Gene +

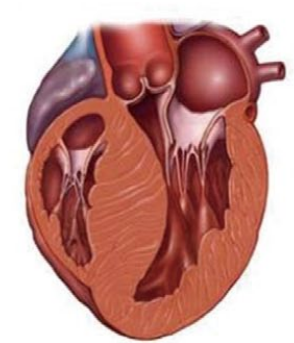

$\sim \mathbf{8 0} \%$ Myofilament

Gene +

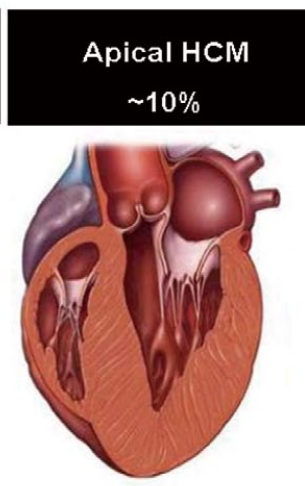

30\% Myofilament

Gene +
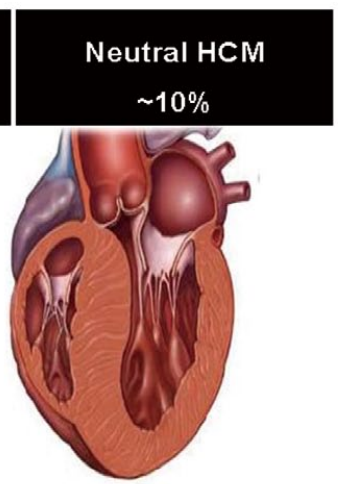

$\sim 40 \%$ Myofilament

Gene +

Figure 4. Septal morphologies in hypertrophic cardiomyopathy $(\mathrm{HCM})$ and the relationship to sarcomeric myofilament-encoding gene mutations. The 4 subgroups of septal morphology in HCM (sigmoidal, reverse curve, apical, neutral) are shown, together with the percentage of $\mathrm{HCM}$ cases represented by each morphology and the likelihood of identifying a mutation in a myofilamentencoding gene. Reproduced with permission from Bos JM et al. ${ }^{52}$

1,000 variants for HCM have been identified to date, $4,13,32,48,49$ most are private and can, therefore, be detected only through comprehensive genetic testing.

Sarcomere variants are identified in up to $60-70 \%$ of patients with HCM who also have a family history, and in 40 $60 \%$ with cases of sporadic HCM. ${ }^{13,49}$ Genotype-phenotype correlations for HCM, however, are incompletely defined, in part because of the private nature of the mutations (in other words, a unique variant). Further, suggestions that a specific mutation in a specific sarcomeric gene will lead to a specific phenotype and specific outcome have been questioned. The pattern and extent of left ventricular (LV) hypertrophy in patients with HCM, as well as outcomes, is heterogeneous even in first-degree relatives. ${ }^{50}$ This heterogeneity has made it difficult to correlate genotype and phenotype, including outcomes. A systematic review and meta-analysis of genotype-phenotype correlations in 2,459 patients and 53 families with sarcomeric gene mutations reported in 18 publications showed that the presence of any sarcomere gene mutation was associated with younger age at presentation (38.4 vs. 46.0 years), family history of HCM (50.6\% vs.23.1\%), family history of SCD (27.0\% vs.14.9\%), and greater LV wall thickness (21.0 vs. $19.3 \mathrm{~mm}){ }^{51}$ The relationship between cardiac morphology, mutated gene, and outcome has also been evaluated. ${ }^{50,52-54}$ Bos et al studied 359 patients, with $34 \%$ being genotype-positive for a putative HCM-associated mutation in 1 or more genes. Echocardiographic reverse curve morphological subtype (Figure 4), age at diagnosis younger than 45 years, maximum LV wall thickness $\geq 20 \mathrm{~mm}$, family history of HCM, and family history of SCD were identified as positive predictors of mutation identification; hypertension was a negative predictor. ${ }^{52,53} \mathrm{~A}$ score, based on the number of predictors of a positive genetic test result, predicted mutation identification in $6 \%$, when only hypertension was present, to $80 \%$ when all 5 positive predictor markers were present.

\section{RCM}

$\mathrm{RCM}$ is the rarest form of cardiomyopathy, characterized by dialted atria, increased ventricular stiffness with normal ventricular wall thickness and systolic function (Figure 2). ${ }^{5,8} \mathrm{SCD}$ or a life-threatening cardiac event because of ventricular arrhythmias or heart block is common, as is HF; death occurs within a few years of diagnosis. ${ }^{5,8}$ Some reports suggest clinical overlap between RCM and HCM. ${ }^{55,56}$

\section{Genetics of RCM}

RCM usually has autosomal dominant inheritance, but autosomal recessive, X-linked and mitochondrial-transmitted disease occurs. Most of the identified genes encode sarcomere or Z-disk proteins, such as TNNI3, TNNT2, MYH7, ACTC1, TPM1, MYL3, and MYL 28,57 (Table 3). Z-disk protein-encoding genes, including MYPN, TTN, and Bag3, have also been identified. ${ }^{4,5,8,13,33}$ Missense variants in DES have been identified in several families with desmin-related myopathy, which can present with RCM, with or without skeletal myopathy and/or atrioventricular block. ${ }^{8}$ Transthyretin (TTR) is associated with amyloid-related RCM. ${ }^{8}$

\section{Noncompaction}

LVNC is a heterogeneous myocardial disorder characterized by prominent trabeculae that are most evident in the LV apex, intratrabecular recesses, and LV myocardium with 2 distinct layers: compacted and noncompacted myocardium

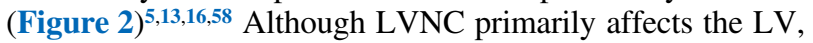
isolated RV and biventricular noncompaction also occurs. ${ }^{58}$ Multiple forms of LVNC occur and include primary myocardial forms, a form associated with arrhythmias, and LVNC associated with congenital heart disease (CHD), including septal defects (atrial and ventricular), hypoplastic left heart syndrome (HLHS), and right heart obstructive abnormalities including pulmonic stenosis (PS) and Ebstein's anomaly (Figure 5), among others. ${ }^{58}$ Outcomes appear to differ based on the specifics of the phenotype.

\section{Genetics of LVNC}

LVNC most commonly has X-linked recessive or autosomal 

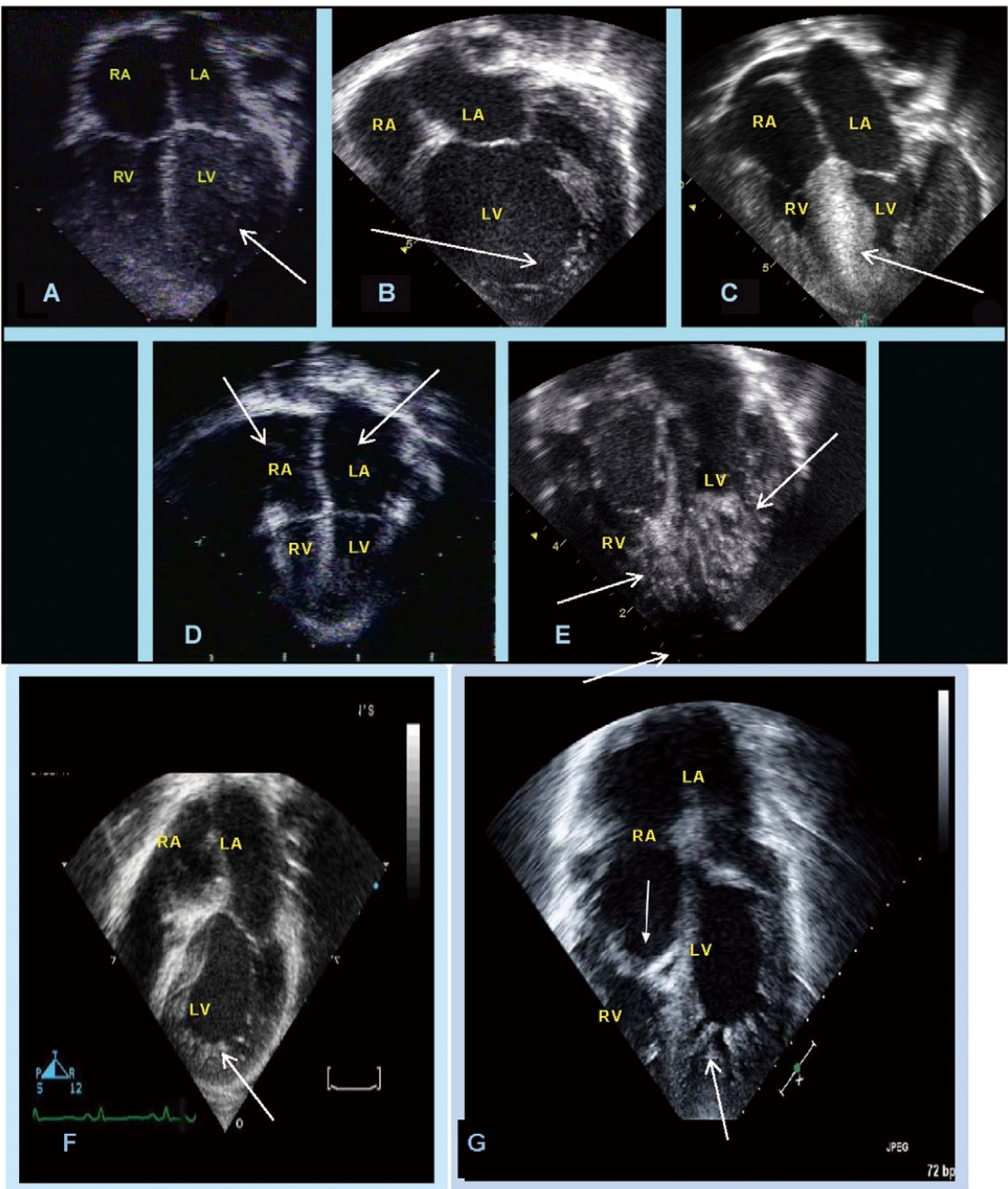

Figure 5. Echocardiographic features of the left ventricular noncompaction (LVNC) phenotype's heterogeneous clinical characteristics. (A) 4-chamber view demonstrates normal atrial and ventricular sizes and thicknesses, with a hypertrabeculated LV wall and apex (arrow). (B) 4-chamber view demonstrates normal atrial sizes with a dilated and hypertrabeculated LV wall and apex (arrow). (C) 4-chamber view demonstrates hypertrophic and hypertrabeculated ventricular walls and apex with a hypertrophic septum (arrow). (D) 4-chamber view demonstrates normal to small ventricular sizes with dilated atria bilaterally (arrows). The LV is hypertrabeculated. (E) 4-chamber view demonstrates normal atrial sizes with severely hypertrabeculated left and right ventricular walls and apices (arrows). (F) 4-chamber view demonstrates normal atrial sizes with tricuspid atresia (no tricuspid valve) and a hypertrabeculated LV wall and apex (arrow). (G) 4-chamber view of Ebstein's anomaly with LVNC, which demonstrates a normal left atrial size with a large right atrium, displaced tricuspid valve towards the right verntricle (closed arrowhead), and a severely hypertrabeculated LV wall and apex (open arrowhead).

dominant inheritance, with reports suggesting $70 \%$ having autosomal dominant and $30 \% \mathrm{X}$-linked inheritance, at least in childhood. ${ }^{58-60}$ Autosomal recessive and mitochondrial inheritance also occurs. ${ }^{58}$ When LVNC is associated with CHD, the congenital cardiac defect may be heterogeneous in families, but this form of LVNC is transmitted as an autosomal dominant trait along with the CHD; affected members may have no CHD at initial evaluation because the cardiac defects include "minor" forms of CHD (small VSDs, ASDs, patent ductus arteriosus), which have spontaneously normalized or penetrance may be reduced, while others may have severe forms of CHD (HLHS, Ebstein's, etc). ${ }^{58,61}$ Ichida et al reported that $44 \%$ of her patients had inherited LVNC, with $70 \%$ having autosomal dominant and $30 \% \mathrm{X}$-linked inheritance. ${ }^{59}$ In addition, patients with chromosomal abnormalities are associated with LVNC.

The first genetic cause of isolated LVNC was initially described by Bleyl et al, when they identified mutations in the $\mathrm{X}$-linked TAZ gene, the gene also responsible for Barth syndrome, in patients and carrier females (Table 3). ${ }^{62}$ Multiple genes causing autosomal dominant LVNC have now been identified, including mutations in genes causing CHD with LVNC. In patients with HLHS and LVNC, the cytoskeletal gene $\alpha$-dystrobrevin has been identified, while mutations in Nkx2.5 in children with LVNC and ASD and MYH7 in patients with LVNC and Ebstein's anomaly have also been reported (Table 3). ${ }^{58,63-66}$ In LVNC without CHD, mutations in the Zline protein-encoding ZASP/LDB3 gene and the sarcomereencoding genes (MYH7, ACTC, TNNT2, MYBPC3, TMP1, 


\begin{tabular}{|ll|}
\hline \multicolumn{2}{|c|}{$\begin{array}{c}\text { Table 5. Genetics of Arrhythmogenic Ventricular } \\
\text { Gene }\end{array}$} \\
CTNNA3 & aT-catenin \\
DES & Desmin \\
DNAJC19 & DnaJ (Hsp40) homolog, subfamily C, member 19 \\
DSC2 & Desmocollin 2 \\
DSG2 & Desmoglin 2 \\
DSP & Desmoplakin \\
JUP & Junctional plakoglobin \\
LMNA & Lamin A/C \\
PKP2 & Plakophilin 2 \\
PKP4 & Plakophilin 4 \\
RYR2 & Ryanodine receptor 2 \\
STRN & Striatin \\
TGF $\beta 3$ & Transforming growth factor- $\beta 3$ \\
TMEM43 & Transmembrane 43 \\
TTN & Titin \\
\hline
\end{tabular}

and TNNI3) appear to account for $20 \%$ or more of cases. ${ }^{58,67,68}$ Hoedemaekers et al additionally demonstrated an association of LVNC with genetic variants in 2 calcium handling genes, as well as TAZ and LMNA, ${ }^{68}$ while Probst et al further showed that sarcomere gene mutations are important in LVNC, showing a prevalence of 29\%, with MYH7 and MYBPC3 most frequently mutated (13\% and $8 \%$, respectively). ${ }^{67}$ Dellefave et al also identified sarcomere mutations in LVNC, including patients presenting with HF in infancy with and without compound heterozygosity. ${ }^{69}$ In addition to sarcomere-encoding genes and the cytoskeleton, mutations in the sodium channel gene, SCN5A, is associated wtih LVNC and rhythm disturbance. ${ }^{63}$ Diagnostic testing in patients with LVNC appears to have a detection rate of clinically significant variants in 35$40 \%$ of individuals, with sarcomere-encoding genes most commonly found to be mutated. ${ }^{4,70}$

\section{Arrhythmogenic Cardiomyopathies}

AVC, previously referred to as arrhythmogenic right ventricular dysplasia or cardiomyopathy and recently re-named in a consensus statement, ${ }^{5}$ constitutes a hereditary cardiomyopathy usually with an autosomal dominant inheritance pattern, although a recessive cardiocutaneous disorder also occurs. ${ }^{71}$ The $\mathrm{RV}$ was initially thought to solely be affected in AVC, and therefore any associated disease of the LV was considered exclusionary for the diagnosis in the original "Task Force criteria" for diagnosis but, more recently, it has been recognized that the LV can also be involved and actually is often associated with severe disease and a worse prognosis. ${ }^{72}$ Classically, however, the RV is dilated with fibrofatty infiltration with no or only minimal LV involvement. ${ }^{5,7}$ Clinically, progressive disease is characterized by systolic impairment and biventricular dilation (with or without a ventricular aneurysm) and clinical features of HF (Figure 2). In most parts of the world, phenotypic expression is more common in men than in women $(2-3: 1) .^{73}$ AVC commonly manifests during late childhood or adolescence, but can also emerge in the elderly, and has a prevalence of $1 / 2,000$, which can be higher in certain geographical regions such as the Veneto region or the Greek island Naxos. ${ }^{74}$ AVC is recognized as a leading cause of SCD in young adults $\leq 35$ years of age and may account for up to $10 \%$ of cardiovas- cular deaths in the $<65$ age group. ${ }^{5}$

\section{Genetics of AVC}

Analyses of first- and second-degree relatives of patients with AVC suggest that up to $50 \%$ of AVC cases are familial.,5,75 AVC is most commonly inherited as an autosomal dominant trait with incomplete penetrance, $5,7,75$ although 2 autosomal recessive forms have been described. ${ }^{71}$ To date, 15 genes have been reported to cause AVC (Table 5).,5,7,13,76 My group and others demonstrated that compound and digenic heterozygosity is involved in AVC pathogenesis in up to $20 \%$ of cases and leads to more severe disease. ${ }^{77,78}$ As penetrance is incomplete, genetically affected relatives often demonstrate variable and mild (or no) phenotype and the prevalence of familial disease is often underestimated in clinical practice. ${ }^{13,73}$

The first gene to be identified in AVC was junctional plakoglobin (JUP) when a homozygous 2-nucleotide deletion in

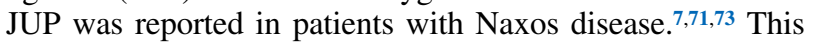
gene encodes the plakoglobin protein, a key protein of the desmosome in the intercalated disk. In autosomal dominant AVC, the desmosomal protein-encoding DSP gene was identified as disease-causing. $7,71,73$

Three groups of desmosomal proteins are known: (1) transmembrane desmosomal cadherins, including DSC2 and DSG2; (2) DSP, a plakin family protein that attaches directly to intermediate filaments (desmin in the myocardium); and (3) linker proteins such as armadillo family proteins, including JUP and plakophilin 2 (PKP2) that mediate interactions between the desmosomal cadherin tails and DSP. ${ }^{71}$ In approximately $80 \%$ of patients with confirmed pathogenic mutations, PKP2, DSP and DSG2 are altered. ${ }^{74}$ Besides desmosomal gene mutations, mutations in genes encoding proteins that interact with desmosomal proteins were found as well, including: (1) the transforming growth factor $\beta 3$ that conveys cytokine-stimulating fibrosis and modulates cell adhesion and growth; (2) the transmembrane protein 43 (TMEM43), which functions as a PPAR- $\gamma$ response element, an adipogenic transcription factor; (3) DES, which binds desmoplakin; and (4) TTN, which bridges the sarcomere along its longitudinal axis and forms a continuous filament along the myofibril (Table 5).4,7,13,73,79,80

Genetically determined disruption of the integrity of the intercalated disk is a key factor promoting the development of AVC and SCD. Recent data indicates that loss of desmosomal integrity can substantially affect gap junctions, sodium channel function and electrical propagation, thereby promoting ventricular arrhythmias in the absence of overt structural damage ${ }^{81,82}$ and thus providing an overlapping phenotype (cardiomyopathy plus arrhythmias) because of disruption of 2 "final common pathways" (desmosome and ion channel). ${ }^{80,83}$

\section{Conclusions}

The cardiomyopathies appear to occur caused by disruption of "final common pathways". These disruptions may be purely genetic causes, such as mutations in a single gene that results in a dysfunctional protein and leads to a domino effect of downstream protein interaction abnormalities and ultimately a phenotype. In other situations, multiple mutations in the same gene (compound heterozygosity) or in different genes (digenic heterozygosity) may lead to a phenotype that may be classic, more severe, or even overlap with other disease forms. In some cases, different intersecting pathways may become disturbed, resulting in complex phenotypes. Further, acquired causes may play a role by causing disruption of these functional pathways. For instance, DCM results from disruption of the "final common 
pathway" linking the sarcomere and sarcolemma, and mutations in the affected genes are responsible for cardiac and skeletal muscle dysfunction. The mechanisms of disease, which include disruption of the linkage because of protein-protein interaction abnormalities that occur with dysfunctional proteins, as well as the interplay of other factors such as mechanical stress and stretch, are being elucidated in detail with the development of animal models of the human disease. Many of the genes identified are now clinically available in fee-forservice laboratories. Novel therapies have resulted from the improved understanding of this clinical phenotype, as noted. Similarly, the genetic basis and mechanistic understanding of $\mathrm{HCM}$ as a disturbance of sarcomere function has occurred over the past 2 decades and genetic tests are clinically available. The development of novel targeted therapies has been somewhat slow in coming but is expected to develop in the near future. In the case of LVNC, the "new kid on the block", genetic understanding is in the early phase. The future of cardiomyopathy care is poised to shift in the next decade because of these new developments, as well as the growing science of stem cell therapy. Because children have "pure" disease states, unfettered by comorbidities, the dream of "cures" of muscle disease (cardiac, skeletal muscle) will likely be realized more fully in this population. We must move towards that goal.

\section{References}

1. Lee CS, Chien CV, Bidwell JT, Gelow JM, Denfeld QE, Creber RM, et al. Comorbidity profiles and inpatient outcomes during hospitalization for heart failure: An analysis of the U.S. Nationwide inpatient sample. BMC Cardiovasc Disord 2014; 14: 73.

2. Shamszad P, Hall M, Rossano JW, Denfield SW, Knudson JD, Penny DJ, et al. Characteristics and outcomes of heart failure-related intensive care unit admissions in children with cardiomyopathy. $J$ Card Fail 2013; 19: 672-677.

3. Cahill TJ, Ashrafian H, Watkins H. Genetic cardiomyopathies causing heart failure. Circ Res 2013; 113: 660-675.

4. Teekakirikul P, Kelly MA, Rehm HL, Lakdawala NK, Funke BH. Inherited cardiomyopathies: Molecular genetics and clinical genetic testing in the postgenomic era. J Mol Diagn 2013; 15: 158-167.

5. Maron BJ, Towbin JA, Thiene G, Antzelevitch C, Corrado D, Arnett $\mathrm{D}$, et al. Contemporary definitions and classification of the cardiomyopathies: An American Heart Association Scientific Statement from the Council on Clinical Cardiology, Heart Failure and Transplantation Committee; Quality of Care and Outcomes Research and Functional Genomics and Translational Biology Interdisciplinary Working Groups; and Council on Epidemiology and Prevention. Circulation 2006 113: 1807-1816.

6. Bowles NE, Bowles KR, Towbin JA. The "final common pathway" hypothesis and inherited cardiovascular disease: The role of cytoskeletal proteins in dilated cardiomyopathy. Herz 2000; 25: 168-175.

7. Ellinor PT, MacRae CA, Thierfelder L. Arrhythmogenic right ventricular cardiomyopathy. Heart Fail Clin 2010; 6: 161-177.

8. Sen-Chowdhry S, Syrris P, McKenna WJ. Genetics of restrictive cardiomyopathy. Heart Fail Clin 2010; 6: 179-186.

9. Towbin JA, Lowe AM, Colan SD, Sleeper LA, Orav EJ, Clunie S, et al. Incidence, causes and outcomes of dilated cardiomyopathy in children. JAMA 2006; 296: 1867-1876.

10. Fatkin D; members of the CSANZ Cardiac Genetic Diseases Council Writing Group. Guidelines for the diagnosis and management of familial dilated cardiomyopathy. Heart Lung Circ 2011; 20: 691693.

11. Givertz MM, Mann DL. Epidemiology and natural history of recovery of left ventricular function in recent onset dilated cardiomyopathies. Curr Heart Fail Rep 2013; 10: 321-330.

12. Dec GW, Fuster V. Idiopathic dilated cardiomyopathy. $N$ Engl J Med 1994; 331: $1564-1575$

13. Ackerman MJ, Priori SG, Willems S, Berul C, Brugada R, Calkins $\mathrm{H}$, et al. HRS/EHRA expert consensus statement on the state of genetic testing for the channelopathies and cardiomyopathies: This document was developed as a partnership between the Heart Rhythm Society (HRS) and the European Heart Rhythm Association (EHRA). Heart Rhythm 2011; 8: 1308-1339.

14. Finsterer J, Stöllberger C, Wahbi K. Cardiomyopathy in neurological disorders. Cardiovasc Pathol 2013; 22: 389-400.
15. Hershberger RE, Lindenfeld J, Mestroni L, Seidman CE, Taylor MR, Towbin JA; Heart Failure Society of America. Genetic evaluation of cardiomyopathy: A Heart Failure Society of America practice guideline. J Card Fail 2009; 15: 83-97.

16. Towbin JA, Bowles NE. The failing heart. Nature 2002; 415: $227-233$.

17. Towbin JA, Hejtmancik JF, Brink P, Gelb B, Zhu XM, Chamberlain JS, et al. X-linked dilated cardiomyopathy (XLCM): Molecular genetic evidence of linkage to the Duchenne muscular dystrophy gene at the Xp21 locus. Circulation 1993; 87: 1854-1865.

18. Muntoni F, Cau M, Ganau A, Congiu R, Arvedi G, Mateddu A, et al. Brief report: Deletion of the dystrophin muscle-specific promoter region associated with X-linked dilated cardiomyopathy. $N$ Engl J Med 1993; 329: 921-925.

19. Diegoli M, Grasso M, Favalli V, Serio A, Gambarin FI, Klersy C, et al. Diagnostic work-up and risk stratification in X-linked dilated cardiomyopathies caused by dystrophin defects. J Am Coll Cardiol 2011; 58: 925-934.

20. Rahimov F, Kunkel LM. The cell biology of disease: Cellular and molecular mechanisms underlying muscular dystrophy. J Cell Biol 2013; 201: 499-510.

21. Constantin B. Dystrophin complex functions as a scaffold for signalling proteins. Biochim Biophys Acta 2014; 1838: 635-642.

22. Chelly J, Desguerre I. Progressive muscular dystrophies. Handb Clin Neurol 2013; 113: $1343-1366$

23. Morales A, Hershberger RE. Genetic evaluation of dilated cardiomyopathy. Curr Cardiol Rep 2013; 15: 375, doi:10.1007/s11886-0130375-1.

24. Mestroni L, Taylor MR. Genetics and genetic testing of dilated cardiomyopathy: A new perspective. Discov Med 2013; 15: 43-49.

25. Garcia-Pavia P, Syrris P, Salas C, Evans A, Mirelis JG, Cobo-Marcos $\mathrm{M}$, et al. Desmosomal protein gene mutations in patients with idiopathic dilated cardiomyopathy undergoing cardiac transplantation: A clinicopathological study. Heart 2011; 97: 1744-1752.

26. Wolf CM, Wang L, Alcalai R, Pizard A, Burgon PG, Ahmad F, et al. Lamin A/C haploinsufficiency causes dilated cardiomyopathy and apoptosis-triggered cardiac conduction system disease. J Mol Cell Cardiol 2008; 44: 293-303.

27. Taylor MR, Slavov D, Ku L, Di Lenarda A, Sinagra G, Carniel E, et al. Prevalence of desmin mutations in dilated cardiomyopathy. Circulation 2007; 115: 1244-1251.

28. Debold EP, Schmitt JP, Patlak JB, Beck SE, Moore JR, Seidman JG, et al. Hypertrophic and dilated cardiomyopathy mutations differentially affect the molecular force generation of mouse alpha-cardiac myosin in the laser trap assay. Am J Physiol Heart Circ Physiol 2007; 293: H284-H291.

29. Ehler E, Perriard JC. Cardiomyocyte cytoskeleton and myofibrillogenesis in healthy and diseased heart. Heart Fail Rev 2000; 5: 259269.

30. Basso C, Czarnowska E, Della Barbera M, Bauce B, Beffagna G, Wlodarska EK, et al. Ultrastructural evidence of intercalated disc remodelling in arrhythmogenic right ventricular cardiomyopathy: An electron microscopy investigation on endomyocardial biopsies. Eur Heart J 2006; 27: 1847-1854.

31. Yang Z, Bowles NE, Scherer SE, Taylor MD, Kearney DL, Ge S, et al. Desmosomal dysfunction due to mutations in desmoplakin causes arrhythmogenic right ventricular dysplasia/cardiomyopathy. Circ Res 2006; 99: 646-655.

32. Purevjav E, Arimura T, Augustin S, Huby AC, Takagi K, Nunoda S, et al. Molecular basis for clinical heterogeneity in inherited cardiomyopathies due to myopalladin mutations. Hum Mol Genet 2012; 21: 2039-2053.

33. Purevjav E, Varela J, Morgado M, Kearney DL, Li H, Taylor MD, et al. Nebulette mutations are associated with dilated cardiomyopathy and endocardial fibroelastosis. J Am Coll Cardiol 2010; 56: $1493-$ 1502 .

34. Fatkin D, Graham RM. Molecular mechanisms of inherited cardiomyopathies. Physiol Ref 2002; 82: 945-980.

35. McNally EM, Golbus JR, Puckelwartz MJ. Genetic mutations and mechanisms in dilated cardiomyopathy. J Clin Invest 2013; 123: $19-$ 26.

36. Olson TM, Michels VV, Thibodeau SN, Tai YS, Keating MT. Actin mutations in dilated cardiomyopathy, a heritable form of heart failure. Science 1998; 280: 750-752.

37. Kamisago M, Sharma SD, DePalma SR, Solomon S, Sharma P, $\mathrm{McD}$ onough $\mathrm{B}$, et al. Mutations in sarcomere protein genes as a cause of dilated cardiomyopathy. N Engl J Med 2000; 343: 1688-1696.

38. Pyle WG, Solaro RJ. At the crossroads of myocardial signaling: The role of Z-discs in intracellular signaling and cardiac function. Circ Res 2004; 94: 296-305. 
39. Knoll R, Hoshijima M, Hoffman HM, Person V, Lorenzen-Schmidt I, Bang ML, et al. The cardiac mechanical stretch sensor machinery involves a $\mathrm{Z}$ disc complex that is defective in a subset of human dilated cardiomyopathy. Cell 2002; 11: 943-955.

40. Vatta M, Sinagra G, Brunelli L, Faulkner G. Remodeling of dystrophin and sarcomeric Z-band occurs in pediatric cardiomyopathies: A unifying mechanism for force transmission defect. J Cardiovasc Med (Hagerstown) 2009; 10: 149-156.

41. Mohapatra B, Jimenez S, Lin JH, Bowles KR, Coveler KJ, Marx JG, et al. Mutations in the muscle LIM protein and $\alpha$-actinin- 2 genes in dilated cardiomyopathy and endocardial fibroelastosis. Mol Genet Metab 2003; 80: 207-215.

42. Lin X, Ruiz J, Bajraktari I, Ohman R, Banerjee S, Gribble K, et al. Z-disc-associated, alternatively spliced, PDZ motif-containing protein (ZASP) mutations in the actin-binding domain cause disruption of skeletal muscle actin filaments in myofibrillar myopathy. $J$ Biol Chem 2014; 289: 13615-13626.

43. Martinelli VC, Kyle WB, Kojic S, Vitulo N, Li Z, Belgrano A, et al. ZASP interacts with the mechanosensing protein Ankrd2 and p53 in the signalling network of striated muscle. PLoS One 2014; 9: e92259, doi:10.1371/journal.pone.0092259.

44. LeWinter MM, Granzier HL. Cardiac titin and heart disease. J Cardiovasc Pharmacol 2014; 63: 207-212.

45. Maron BJ, Maron MS. Hypertrophic cardiomyopathy. Lancet 2013; 381: $242-255$.

46. O'Mahony C, Elliott PM. Prevention of sudden cardiac death in hypertrophic cardiomyopathy. Heart 2014; 100: $254-260$.

47. Marston S, Copeland O, Jacques A, Livesey K, Tsang V, McKenna WJ, et al. Evidence from human myectomy samples that MYBPC3 mutations cause hypertrophic cardiomyopathy through haploinsufficiency. Circ Res 2009; 105: 219-222.

48. Lopes LR, Zekavati A, Syrris P, Hubank M, Giambartolomei C, Dalageorgou C, et al. Genetic complexity in hypertrophic cardiomyopathy revealed by high-throughput sequencing. J Med Genet 2013; 50: $228-239$.

49. Ho CY. Genetics and clinical destiny: Improving care in hypertrophic cardiomyopathy. Circulation 2010; 122: 2430-2440.

50. Bos JM, Will ML, Gersh BJ, Kruisselbrink TM, Ommen SR, Ackerman MJ. Characterization of a phenotype-based genetic test prediction score for unrelated patients with hypertrophic cardiomyopathy. Mayo Clin Proc 2014; 89: 727-737.

51. Lopes LR, Rahman MS, Elliott PM. A systematic review and metaanalysis of genotype-phenotype associations in patients with hypertrophic cardiomyopathy caused by sarcomeric protein mutations. Heart 2013; 99: 1800-1811.

52. Bos JM, Towbin JA, Ackerman MJ. Diagnostic, prognostic, and therapeutic implications of genetic testing for hypertrophic cardiomyopathy. J Am Coll Cardiol 2009; 54: 201 - 211.

53. Theis JL, Bos JM, Bartleson VB, Will ML, Binder J, Vatta M, et al. Echocardiographic-determined septal morphology in Z-disc hypertrophic cardiomyopathy. Biochem Biophys Res Commun 2006; 351: 896-902.

54. Geske JB, Bos JM, Gersh BJ, Eidem BW, Ackerman MJ. Deformation patterns in genotyped patients with hypertrophic cardiomyopathy. Eur Heart J Cardiovasc Imaging 2014; 15: 456-465.

55. Rivenes SM, Kearney DL, Smith EO, Towbin JA, Denfield SW. Sudden death and cardiovascular collapse in children with restrictive cardiomyopathy. Circulation 2000; 102: 876-882.

56. Walsh MA, Grenier MA, Jefferies JL, Towbin JA, Lorts A, Czosek RJ. Conduction abnormalities in pediatric patients with restrictive cardiomyopathy. Circ Heart Fail 2012; 5: 267-273.

57. Caleshu C, Sakhuja R, Nussbaum RL, Schiller NB, Ursell PC, Eng $\mathrm{C}$, et al. Furthering the link between the sarcomere and primary cardiomyopathies: Restrictive cardiomyopathy associated with multiple mutations in genes previously associated with hypertrophic or dilated cardiomyopathy. Am J Med Genet A 2011; 155A: 2229-2235.

58. Towbin JA. Left ventricular noncompaction: A new form of heart failure. Heart Fail Clin 2010; 6: 453-469.

59. Ichida F, Hamamichi Y, Miyawaki T, Ono Y, Kamiya T, Akagi T, et al. Clinical features of isolated noncompaction of the ventricular myocardium: Long-term clinical course, hemodynamic properties, and genetic background. J Am Coll Cardiol 1999; 34: 233-240.

60. Sasse-Klaassen S, Gerull B, Oechslin E, Jenni R, Thierfelder L. Isolated noncompaction of the left ventricular myocardium in the adult is an autosomal dominant disorder in the majority of patients. Am J Med Genet A 2003; 119A: 162-167.

61. Stahli BE, Gebhard C, Biaggi P, Klaassen S, Valsangiacomo Buechel $\mathrm{E}$, Attenhofer Jost CH, et al. Left ventricular non-compaction: Prevalence in congenital heart disease. Int J Cardiol 2013; 167: 2477 2481.
62. Bleyl SB, Mumford BR, Brown-Harrison MC, Pagotto LT, Carey JC, Pysher TJ, et al. Xq28-linked noncompaction of the left ventricular myocardium: Prenatal diagnosis and pathologic analysis of affected individuals. Am J Med Genet 1997; 72: 257-265.

63. Udeoji DU, Philip KJ, Morrissey RP, Phan A, Schwarz ER. Left ventricular noncompaction cardiomyopathy: Updated review. Ther Adv Cardiovasc Dis 2013; 7: 260-273.

64. Ouyang P, Saarel E, Bai Y, Luo C, Lv Q, Xu Y, et al. A de novo mutation in NKX2.5 associated with atrial septal defects, ventricular noncompaction, syncope and sudden death. Clin Chim Acta 2011; 412: $170-175$.

65. Postma AV, van Engelen K, van de Meerakker J, Rahman T, Probst $\mathrm{S}$, Baars MJ, et al. Mutations in the sarcomere gene MYH7 in Ebstein anomaly. Circ Cardiovasc Genet 2011; 4: 43-50.

66. Vermeer AM, van Engelen K, Postma AV, Baars MJ, Christiaans I, De Haij S, et al. Ebstein anomaly associated with left ventricular noncompaction: An autosomal dominant condition that can be caused by mutations in MYH7. Am J Med Genet C Semin Med Genet 2013; 163C: $178-184$

67. Probst S, Oechslin E, Schuler P, Greutmann M, Boyé P, Knirsch W, et al. Sarcomere gene mutations in isolated left ventricular noncompaction cardiomyopathy do not predict clinical phenotype. Circ Cardiovasc Genet 2011; 4: 367-374.

68. Hoedemaekers YM, Caliskan K, Michels M, Frohn-Mulder I, van der Smagt JJ, Phefferkorn JE, et al. The importance of genetic counseling, DNA diagnostics, and cardiologic family screening in left ventricular noncompaction cardiomyopathy. Circ Cardiovasc Genet 2010; 3: 232-239.

69. Dellefave LM, Pytel P, Mewborn S, Mora B, Guris DL, Fedson S, et al. Sarcomere mutations in cardiomyopathy with left ventricular hypertrabeculation. Circ Cardiovasc Genet 2009; 2: 442-449.

70. Shieh JT. Implications of genetic testing in noncompaction/hypertrabeculation. Am J Med Genet C Semin Med Genet 2013; 163C: 206-211.

71. Protonotarios N, Tsatsopoulou A. Naxos disease and Carvajal syndrome: Cardiocutaneous disorders that highlight the pathogenesis and broaden the spectrum of arrhythmogenic right ventricular cardiomyopathy. Cardiovasc Pathol 2004; 13: 185-194.

72. Marcus FI, McKenna WJ, Sherrill D, Basso C, Bauce B, Bluemke DA, et al. Diagnosis of arrhythmogenic right ventricular cardiomyopathy/dysplasia: Proposed modification of the task force criteria. Circulation 2010; 121: $1533-1541$.

73. Azaouagh A, Churzidse S, Konorza T, Erbel R. Arrhythmogenic right ventricular cardiomyopathy/dysplasia: A review and update. Clin Res Cardiol 2011; 100: 383-394.

74. Herren T, Gerber PA, Duru F. Arrhythmogenic right ventricular cardiomyopathy/dysplasia: A not so rare "disease of the desmosome" with multiple clinical presentations. Clin Res Cardiol 2009; 98: 141 158.

75. Hamid MS, Norman M, Quraishi A, Firoozi S, Thaman R, Gimeno JR, et al. Prospective evaluation of relatives for familial arrhythmogenic right ventricular cardiomyopathy/dysplasia reveals a need to broaden diagnostic criteria. J Am Coll Cardiol 2002; 40: 1445-1450.

76. Te Rijdt WP, Jongbloed JD, de Boer RA, Thiene G, Basso C, van den Berg MP, et al. Clinical utility gene card for: Arrhythmogenic right ventricular cardiomyopathy (ARVC). Eur J Hum Genet 2014; 22, doi:10.1038/ejhg.2013.124.

77. Xu T, Yang Z, Vatta M, Rampazzo A, Beffagna G, Pilichou K, et al. Compound and digenic heterozygosity contributes to arrhythmogenic right ventricular cardiomyopathy. J Am Coll Cardiol 2010; 55: 587-597.

78. Bauce B, Nava A, Beffagna G, Basso C, Lorenzon A, Smaniotto G, et al. Multiple mutations in desmosomal proteins encoding genes in arrhythmogenic right ventricular cardiomyopathy/dysplasia. Heart Rhythm 2010; 7: 22-29.

79. Patel DM, Green KJ. Desmosomes in the heart: A review of clinical and mechanistic analyses. Cell Commun Adhes 2014; 21: 109-128.

80. Vatta M, Marcus F, Towbin JA. Arrhythmogenic right ventricular cardiomyopathy: A 'final common pathway' that defines clinical phenotype. Eur Heart J 2007; 28: 529-530

81. Delmar M, McKenna WJ. The cardiac desmosome and arrhythmogenic cardiomyopathies: From gene to disease. Circ Res 2010; 107: $700-714$.

82. Noorman M, Hakim S, Kessler E, Groeneweg JA, Cox MG, Asimaki A, et al. Remodeling of the cardiac sodium channel, connexin 43 , and plakoglobin at the intercalated disk in patients with arrhythmogenic cardiomyopathy. Heart Rhythm 2013; 10: 412-419.

83. Towbin JA, Lorts A. Arrhythmias and dilated cardiomyopathy common pathogenetic pathways? J Am Coll Cardiol 2011; 57: 21692171. 